\title{
ВЛИЯНИЕ ИЗМЕНЕНИЯ КУРСА НАЦИОНАЛЬНОЙ ВАЛЮТЫ НА МАКРОЭКОНОМИЧЕСКИЕ ПОКАЗАТЕЛИ: ОЦЕНКА НА ОСНОВЕ МЕТОДОЛОГИИ «ЗАТРАТЫ - ВЫПУСК»
}

\author{
В.А. Пархименко, А.А. Быков*
}

Дана количественная оценка влияния колебаний валютного курса на основные макроэкономические показатели, опираясь на методологию межотраслевого баланса. Оценка осуществляется путем последовательного решения соответствующих двойственной и прямой задач Леонтьева на основе официальных данных межотраслевого баланса Республики Беларусь за 2018 г. В качестве основных макроэкономических показателей рассматриваются: совокупный выпуск, валовая добавленная стоимость, объем импорта и экспорта, сальдо торгового баланса, уровень потребительских цен, конечный спрос на внутреннем рынке. По итогам осуществленных расчетов построены соответствующие функции реакции, отражающие изменение указанных макроэкономических показателей при разных уровнях обменного курса белорусского рубля. В статье также рассматриваются ограничения предлагаемой методологии и направления будущих исследований.

Ключевые слова: анализ «затраты - выпуск», девальвация, инфляция, макроэкономические показатели, национальная валюта, обменный курс, режим валютного курса, сальдо торгового баланса, экономический рост.

JEL-классификация: C67, D57, E17, O41.

DOI: $10.46782 / 1818-4510-2020-3-58-73$

Материал поступил 2.09.2020 2.

\section{Постановка проблемь}

В Беларуси курс национальной валюты - важный маркер экономической и финансовой стабильности, а термин «девальвация» уже давно вышел за пределы академических кабинетов и широко используется в бытовой лексике. Основной причиной этого стали ряд существенных изменений курса белорусского рубля за последние десять лет, психологически болезненно воспринятых населением.

Так, в самом начале января 2009 г. курс белорусского рубля одномоментно упал с 2200 до 2650 руб. за 1 долл. США, т. е. на 20\%. В течение двух последующих месяцев падение продолжилось и достигло в конце февраля уровня в 2858 руб. за 1 долл.
США ${ }^{1}$, тем самым общее изменение составило $30 \%$.

В мае 2011 г. курс белорусского рубля с 3155 снизился до 4930 за одни сутки ${ }^{2}$, т. е. на $56 \%$. В конце октября курс достиг отметки в 8500 руб. за 1 долл. США ${ }^{3}$, т. е. общее падение с начала 2011 г. составило 283\%.

В декабре 2014 г. вслед за «обвалом» российского рубля курс белорусской валюты стал падать и в самом конце года буквально за сутки упал на 7,5\% - с 11030 до 11850 бел. руб. за 1 долл. США продолжилось и в 2015 г., когда в конце

\footnotetext{
1 URL: https://www.nbrb.by/statistics/rates/ ratesdaily.asp

2 Там же.

3 Там же.

4 Там же.
}

* Пархименко Владимир Анатольевич (parkhimenko@bsuir.by), кандидат экономических наук, доцент, Белорусский государственный университет информатики и радиоэлектроники (г. Минск, Беларусь);

Быков Алексей Александрович (aliaksei.bykau@yandex.ru), доктор экономических наук, профессор, Белорусский государственный экономический университет (г. Минск, Беларусь). 
января курс достиг уровня в 15400 руб. за 1 долл. США ${ }^{5}$, т. е. упал еще на $30 \%$.

Высокие темпы девальвации рубля обычно связывают с относительно мягкой денежно-кредитной политикой, которая проявлялась в росте денежной массы и установлении относительно низкой ставки рефинансирования Национального банка, в сравнении с инфляцией. Такая политика в краткосрочном периоде способствовала экономическому росту, однако во время снижения объемов экспорта приводила к ухудшению платежного баланса, что впоследствии создавало давление на валютный курс и проявлялось в девальвации рубля. Сама девальвация создавала предпосылки к улучшению состояния платежного баланса за счет роста экспорта и снижения импорта. Однако отсутствие финансовой стабильности негативно сказывалось на общем состоянии финансовой системы страны, инвестиционной привлекательности и деловом климате.

С декабря 2015 г. одним из приоритетов для развития белорусской экономики стала политика финансовой стабильности, подразумевающая ограничение денежного стимулирования и применение исключительно рыночных механизмов регулирования финансовых рынков.

В Республике Беларусь в настоящее время используется режим плавающего обменного курса, который, однако, не может рассматриваться как полностью свободный, так как в соответствии с курсовой политикой он подразумевает, что «Национальный банк не устанавливает какие-либо цели по уровню курса или темпам его изменения. Динамика курса белорусского рубля формируется под воздействием рыночных сил - соотношения спроса на иностранную валюту и ее предложения на внутреннем валютном рынке. Исходя из этого, изменение курса может быть обусловлено достаточно широким набором факторов, влияющих на данное соотношение» ${ }^{6}$. Так, изменение курса белорусского рубля по отношению к отдельным иностранным валютам (например, к доллару США) может быть связано как с воздействием внутренних факторов, так и с динамикой курсов на мировых рынках и экономической ситуа-

\footnotetext{
${ }^{5}$ URL: https://www.nbrb.by/statistics/rates/

${ }^{6}$ URL: https://www.nbrb.by/mp/target/exrate-policy
}

цией в странах, по отношению к валютам которых он устанавливается. «Использование гибкого курса выступает в роли своего рода «автоматического стабилизатора» при воздействии внешних шоков и снижает влияние их негативных последствий на экономику страны. Реализация курсовой политики в режиме плавающего курса допускает проведение валютных интервенций с целью сглаживания резких колебаний курса в ходе торгов иностранными валютами на ОАО «Белорусская валютно-фондовая биржа», а также приобретение иностранной валюты для пополнения золотовалютных резервов при устойчивом превышении ее предложения над спросом на внутреннем валютном рынке. Механизм принятия решений о проведении Национальным банком операций по покупке и продаже иностранной валюты является формализованным и регламентируется правилами курсовой политики Национального банка» ${ }^{7}$.

Причинами девальвации становилась не только внутренняя экономическая политика, но также и внешние шоки в виде снижения экспорта ввиду общего снижения спроса на мировых рынках (2009-2010 гг.), а также девальвации российского рубля (2015 г.). Переход Нацбанка к режиму плавающего валютного обменного курса и общий приоритет финансовой стабильности для экономики позволили максимально снизить воздействие внешних шоков на курс, а также почти полностью исключить негативное влияние внутренних монетарных факторов. Между тем ситуация со снижением обменного курса рубля летом 2020 г. показала, что в условиях одномоментного воздействия совокупности внешних и внутренних негативных факторов финансовая стабильность может быть нарушена. К таким негативным факторам следует отнести: последствия «коронакризиса» в виде общемирового снижения спроса, цен на сырье, объемов грузоперевозок; последствия политического кризиса в Беларуси в виде общего снижения потребительских настроений; девальвационные ожидания.

Иными словами, сложилась ситуация, когда валютный курс нельзя назвать промежуточным звеном в причинно-следственной цепочке факторов экономического развития, таких как изменение экспортных доходов или

\footnotetext{
7 URL: https://www.nbrb.by/mp/target/exrate-policy
} 
стимулирование внутреннего спроса. В данном случае факторов слишком много, поэтому изменение курса может рассматриваться как самостоятельная переменная, влияющая на макроэкономические показатели.

Глубокое исследование факторов, непосредственно влияющих на курс белорусского рубля, не является целью данной статьи. Нами поставлена задача проанализировать возможные последствия изменений валютного обменного курса для экономики на основе оценки количественной взаимосвязи данного индикатора с такими показателями, как объем экспорта и импорта, внешнеторговое сальдо, промежуточный и конечный спрос, ВДС и ВВП. В качестве инструментария анализа мы использовали методологию межотраслевого баланса, которая позволяет рассчитывать изменения цен на отечественные и импортные товары и услуги при изменении валютного курса, с детализацией по всем 83 видам экономической деятельности, выделяемым в отечественных таблицах «Затраты - Выпуск».

\section{Обзор литературы}

С точки зрения экономической теории, обменный курс (exchange rate) - это цена такого товара, как национальная или зарубежная валюта, складывающаяся под воздействием спроса и предложения. Два основных мотива, лежащих в основе спроса на национальную валюту, - это приобретение зарубежными контрагентами отечественных товаров и услуг, а также покупка отечественных ценных бумаг. Предложение национальной валюты формируют те субъекты, которые желают приобрести зарубежные товары и услуги и зарубежные ценные бумаги. Таким образом, импорт и экспорт, а также ввоз и вывоз капитала основные фундаментальные факторы, действующие на валютном рынке.

На практике, однако, для прогнозирования обменного курса аналитики, как правило, не пытаются оценить функции спроса и предложения на валютном рынке, а используют косвенные оценки иных факторов.

Так, с точки зрения (Ca'Zorzi, Cap, Mijakovic, Rubaszek, 2020), среди основных существующих подходов к долгосрочному прогнозированию реального обменного курса стоит выделить: подход, основанный на относительном изменении индексов цен (уровня инфляции) в разных странах (Purchasing Power Parity, PРP); подход, учитывающий ВВП на душу населения, чистые иностранные активы, соотношение импортных и экспортных цен (terms of trade) - так называемый поведенческий равновесный валютный курс (Behavioral Equilibrium Exchange Rate, BEER); подход, ориентированный на состояние счета текущих операций и иные макроэкономические параметры - так называемый обменный курс в условиях макроэкономического равновесия (Macroeconomic Balance approach). При этом авторы приходят к выводу, что последний подход дает наименее точные предсказания, a подходы BEER и PPP близки по своей прогностической силе (Ca'Zorzi, Cap, Mijakovic, Rubaszek, 2020).

Анализ, проведенный (Hauner, Lee, Takizawa, 2014), трех классов наиболее популярных моделей прогнозирования обменного курса (основанный на учете разного уровня инфляции - purchasing power parity; основанный на учете разницы в процентных ставках в разных странах - interest rate parity; основанный на учете нескольких макроэкономических параметров behavioral models), показал, что только два фактора зарекомендовали себя за многие годы и наиболее точно предсказывают динамику обменного курса - уровень инфляции и темп роста ВВП.

На практике существует множество разновидностей так называемых валютных режимов, которые, по сути, определяют правила поведения центрального банка на валютном рынке. В частности, специалисты МВФ выделяют 2 режима жесткой привязки (hard pegs), 5 режимов мягкой привязки (soft pegs), 2 плавающих режима (floating) и оставляют для всех остальных возможных на практике режимов категорию «residuals» (Veyrune, Kokenyne, Habermeier, Anderson, 2009).

Еще одну классификацию («естественную», как ее описывают сами авторы) можно посмотреть у (Reinhart, Rogoff, 2004), которые выделяют 14 возможных на практике вариантов валютного режима. 
Не вдаваясь в тонкости и нюансы, рассмотрим два «чистых» полярных случая, возможных с точки зрения абстрактной теории и достаточных для целей настоящее статьи. Речь идет о фиксированном и плавающем валютном курсе.

В странах с плавающим режимом валютного курса центральный банк не вмешивается (или вмешивается незначительно и, как правило, только в случае какихто эксцессов) в работу рыночного механизма, т. е. спроса и предложения. Обменный курс определяется взаимодействием стихийных спроса и предложения на валютном рынке. В такой ситуации курс может быть подвержен значительным колебаниям (шокам) и даже в относительно стабильное время является динамичной величиной. Такая динамика, однако, позволяет экономике осуществлять адаптацию к внешним изменяющимся условиям.

В странах с фиксированным режимом валютного курса центральный банк привязывает стоимость национальной валюты к курсу валюты или корзины валют страны или стран с низким уровнем инфляции. Для противодействия естественным колебаниям курса под воздействием спроса и предложения, т. е. его сохранения на заданном уровне, центробанк использует валютные интервенции - покупает (в ситуации излишка) или продает (в ситуации дефицита) валюту по фиксированному курсу. Для использования данного режима страна должна обладать существенными золотовалютными резервами для противодействия шокам на валютном рынке ${ }^{8}$. (Термин «девальвация», строго говоря, применим только для ситуации, когда при режиме фиксированного валютного курса центральный банк объявляет о новой более низкой цели обменного курса.)

Последствия изменений валютного курса в части его влияния на основные макроэкономические показатели глубоко проанализированы в рамках посткейнсианских моделей экономического роста и регулирования платежного баланса. В данных моделях валютный обменный курс является важнейшим параметром, связывающим экономический рост с совокупным спро-

${ }^{8}$ URL: https://www.nbrb.by/mp/target/general-character сом и состоянием платежного баланса. Снижение курса национальной валюты (девальвация) приводит к относительному снижению цен на отечественные товары и услуги на внутреннем и внешнем рынках в сравнении с импортными аналогами, что должно вызвать рост спроса на отечественные продукты и снижение спроса на импортные. Результатом должно стать увеличение внешнеторгового профицита или снижение его дефицита. С другой стороны, относительный рост экспорта приводит к укреплению национальной валюты, следствием чего становится выравнивание цен на отечественные и импортные продукты.

Широко известен предложенный С. Александером абсорбционный подход к регулированию платежного баланса (Alexander, 1952). Девальвация эффективна для экономик с высокой долей экспортных доходов в ВВП. Реальный девальвационный эффект, стабилизирующий платежный баланс, получает лишь экспортный сектор экономики как совокупность производственных цепочек, объединяющих производителей отечественных продуктов, которые поставляются на экспорт. Если же основная доля ВВП создается за счет внутреннего спроса (в терминологии Александера названного абсорбцией), то девальвация вызовет снижение конечного потребления и валового накопления, что приведет не только к сокращению импорта, но и к экономическому спаду.

Модель, или так называемый закон ограниченности экономического роста платежным балансом Э. Тирлволла, постулирует слабую результативность денежного стимулирования роста в развивающихся экономиках (Thirlwall, 2003). Довольно часто в случае снижения экспортных доходов правительство и центральный банк пытаются «перезапустить» экономический рост за счет стимулирования спроса на отечественные товары и услуги на внутреннем рынке, увеличивая объем денежного предложения. Первоначально такие меры приносят эффект, поскольку рост доходов ведет к росту спроса, объемов выпуска отечественных продуктов и росту ВВП. Побочным эффектом становится рост спроса на импорт и внешнеторговый дефицит, который в итоге подталки- 
вает рынок к снижению обменного курса национальной валюты. После девальвации внутренний рынок сжимается, и рост ВВП за счет денежного предложения прекращается. Таким образом, согласно закону Тирлволла, денежное стимулирование внутреннего спроса имеет весьма ограниченные возможности для применения в развивающихся экономиках, когда валютный курс зависит от изменений внешнеторгового сальдо.

Вместе с тем посткейнсианские модели роста, основанного на спросе, показали, что девальвация может стать эффективным инструментом краткосрочного роста не только экспорта, но и ВВП для экономик с высокой долей оплаты труда в доходах (Ribeiro, McCombie, Lima, 2017).

В работе (Быков, Шаблинская, 2020) проведена оценка вклада экспорта и внутреннего спроса в формирование ВВП белорусской экономики. Установлено, что в среднем с 2010 по 2017 г. вклад экспорта в ВВП составил $39 \%$, а вклад внутреннего спроса $61 \%$. Также показано, что сильное влияние на экономический рост оказывают два монетарных параметра: предложение денежной массы и девальвация рубля. Через приращение денежной массы Нацбанк увеличивает потребительский и инвестиционный спрос, что ведет к экономическому росту в краткосрочном периоде. Девальвация служит защитой от ее перегрева, она замедляет рост, но стабилизирует платежный баланс.

Население обычно психологически плохо воспринимает резкое одномоментное падение курса национальной валюты, так как оно приводит к росту цен, особенно на потребительские импортные товары, падению доходов и сбережений, выраженных в «твердой валюте», повышает общую экономическую неопределенность и панические настроения.

С точки зрения теории, однако, естественное или вынужденное изменение курса, по сути, является необходимым механизмом перехода экономики в новое равновесное состояние, т. е. стабилизации экономики при внешних или внутренних шоках. Как правило, падение курса национальной валюты делает более привлекательными экспортируемые отечественные товары и услуги и менее привлекательными импортируемые - тем самым происходит уменьшение дефицита сальдо торгового баланса, увеличиваются золотовалютные резервы.

В литературе описано необходимое условие для полноценного функционирования этого механизма, так называемое условие Маршалла-Лернера, согласно которому «снижение стоимости национальной валюты приводит к улучшению торгового баланса, если сумма абсолютных эластичностей национального спроса на импорт и иностранного спроса на национальный экспорт больше единицы» ${ }^{9}$.

Показатели эластичности импорта, экспорта, потребительского и инвестиционного спроса по цене и по доходу занимают центральное место в посткейнсианских моделях экономического роста. Обычно они являются расчетными величинами, что не исключает, однако, их использования в качестве экзогенных переменных. В данном случае значения эластичностей могут быть установлены экспертным путем по каждому из продуктов.

\section{Общая схема расчетов}

Предлагаемая и используемая в данной статье методология оценки влияния изменения курса национальной валюты на макроэкономические показатели может быть представлена в виде схемы (рис. 1).

В качестве заданной извне величины выступает изменение обменного курса (шаг № 1), на основании которого рассчитываются новые цены на отечественные товары и услуги вследствие автоматического удорожания импортируемых благ (шаг № 2). Далее осуществляются оценки изменения объемов конечного спроса на внутреннем и внешнем рынках (шаг № 3) на базе новых цен, полученных на предыдущем шаге. Наконец, исходя из изменившихся объемов спроса, производятся оценки выпуска товаров и услуг и другие макроэкономические показатели (шаг № 4).

Следует отметить, что в реальной действительности экономика как гигантская вычислительная машина (если пользовать-

${ }^{9}$ URL: https://en.wikipedia.org/wiki/Marshall\%E2\% 80\%93Lerner condition 


\begin{tabular}{|c|}
\hline $\begin{array}{c}\text { Внешние и внутренние факторы, } \\
\text { влияющие на курс рубля }\end{array}$ \\
\hline Изменение курса национальной валюты \\
\hline \multicolumn{2}{|c|}{ Модель 1} \\
(Двойственная модель Леонтьева) \\
\hline $\begin{array}{c}\text { Мовые цены на отечественные товары } \\
\text { (на внутреннем и внешнем рынках) }\end{array}$ \\
\hline \multicolumn{2}{|c|}{ Модель 2} \\
(Коэффициенты ценовой эластичности спроса) \\
\hline $\begin{array}{c}\text { Новые объемы конечного спроса } \\
\text { (на внутреннем и внешнем рынках) }\end{array}$ \\
\hline \multicolumn{2}{|c|}{ Модель 3} \\
\hline (Базовая модель Леонтьева)
\end{tabular}

Рис. 1. Общая логика оценки влияния изменения курса национальной валюты на макроэкономические показатели

Источник. Авторская разработка.

ся известной метафорой В.В. Леонтьева) будет вновь и вновь осуществлять подобные итерации «расчетов», так как очевидно, что здесь существуют циклы обратной связи. В принципе такое возможно и в прогнозных расчетах, однако авторы данной статьи ограничились лишь одним «проходом» по предложенному алгоритму.

\section{Модель 1 \\ (Әвойственная модель Леонтьева)}

Как известно, двойственная модель Леонтьева (Leontief, 1986) описывает ценовые пропорции, сложившиеся в национальной экономике, и в классическом виде может быть записана следующим образом:

$$
P=A^{T} \cdot P+V
$$

где $P$ - вектор-столбец цен по $n$ отраслям;

$V$ - вектор-столбец суммы валовой добавленной стоимости на единицу продукции;

$A^{T}$ - транспонированная матрица прямых (материальных) затрат на единицу выпуска (размерностью $n \times \mathrm{x} n$ ).

По сути, двойственная модель Леонтьева фиксирует следующую экономическую логику. Цена единицы выпуска равна сумме прямых затрат и валовой добавленной стоимости. При этом обеспечивается балансировка всех цен по всем отраслям экономики, так как выпуск одной отрасли (и соответствующая цена выпуска) может выступать прямыми затратами для другой отрасли, т. е. входит в прямые затраты и, тем самым, в итоговую цену выпуска этой отрасли, который далее может использоваться третьей отраслью и т. д.

Поскольку в большинстве случаев исходными данными для модели служат не физические (натуральные) данные, как в самом первоначальном подходе Леонтьева, а данные межотраслевого баланса в стоимостном, то под ценами, строго говоря, понимаются не цены как таковые, а индексы цен (Miller, Blair, 2009).

Для белорусского межотраслевого баланса уравнение (1) нужно переписать с учетом наличия отдельных данных по прямым затратам отечественных и импортных товаров и услуг, а также чистым налогам на продукты, которые используются в промежуточном потреблении:

$$
P_{\text {отеч }}=A_{\text {отеч }}^{T} \cdot P_{\text {отеч }}+A_{\text {имп }}^{T} \cdot P_{\text {имп }}+T+V \text {, }
$$

где $P_{\text {отеч }}-$ вектор-столбец цен на отечественные товары и услуги;

$A_{\text {отеч }}^{T}$ - транспонированная матрица прямых затрат отечественных товаров и услуг на 1 руб. выпущенных отечественных товаров и услуг;

$A_{\text {имп }}^{T}$ - транспонированная матрица прямых затрат импортных товаров и услуг на 1 руб. выпущенных отечественных товаров и услуг;

$P_{\text {имп }}-$ вектор-столбец цен на импортные товары и услуги (в рублях);

$V$ - вектор-столбец суммы валовой добавленной стоимости на 1 руб. выпуска отечественных товаров и услуг;

$T$-вектор-столбец суммы чистых налогов на продукты, используемые в промежуточном потреблении, на 1 руб. выпуска отечественных товаров и услуг.

Решение (2) относительно векторастолбца цен отечественных товаров и услуг даст следующее уравнение:

$$
P_{\text {отеч }}=\left(E-A_{\text {отеч }}^{T}\right)^{-1} \cdot\left(A_{\text {имп }}^{T} \cdot P_{\text {имп }}+V+T\right),
$$


где $E$ - единичная матрица соответствующей размерности.

Как следует из (3), рост цен на отечественные товары и услуги зависит от роста цен на импортные товары и услуги, используемые в промежуточном потреблении. При этом, чем более импортоемкие отечественные товары и услуги, тем они будут больше подвержены влиянию. (По всей видимости, рост цены будет линейно связан с полной импортоемкостью товара или услуги, но это вопрос для другой публикации.)

Полагая в самом простом случае, что девальвация национальной валюты (белорусского рубля) будет означать одинаковый рост всех индексов цен на импортные товары и услуги, содержащихся в векторестолбце $P_{\text {имп }}$, то справедливо следующее:

$$
P_{\text {имп }}=\left(P_{\text {имп1 } 1}, P_{\text {имп } 2}, \ldots P_{\text {импп }}\right)^{T}=(\delta, \delta, \ldots, \delta)^{T},
$$

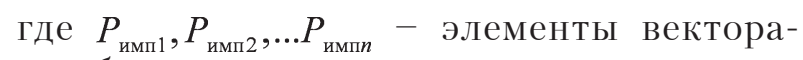
столбца индексов цен на импортные товары и услуги;

$\delta$ - коэффициент девальвации (отношение текущего курса национальной валюты к курсу базового периода), при этом $\delta \in(0,+\infty)$.

Безусловно, подобная логика исходит из нереалистичного представления о том, что все товары и услуги экспортируются и импортируются в ценах, выраженных лишь в одной иностранной валюте, например долларе США. Или (авторы склонны именно к такой интерпретации) обменный курс в рамках данной статьи понимается как курс к некоей корзине валют, что позволяет, пусть и грубо, описать удорожание или удешевление импортных товаров и услуг в среднем. О более реалистичном случае будет сказано ниже.

\section{Модель 2 (коэффициенты ценовой эластичности спроса)}

Исходя из ценовых индексов на отечественные товары и услуги, которые фиксируют изменение цен вследствие изменения курса национальной валюты, можно сделать оценку изменения спроса на эти товары и услуги на внутреннем и внешнем рынках на основе функции спроса.

В данной статье предлагается использовать функция спроса с постоянной элас- тичностью, которую в общем виде можно представить как:

$$
q(p)=k \cdot p^{-r},
$$

где $q(p)$ - объем спроса в натуральных единицах;

$k$ - константа;

$p$ - цена единицы товара/услуги;

$r$ - коэффициент эластичности, $r \in(0 ;+\infty)$.

Переходя к индексам цен и объемов, а также полагая для упрощения, что $k=1$, получим в общем виде следующее уравнение:

$$
i_{q}=\left(i_{p}\right)^{-r},
$$

где $i_{q}$ - индекс физического объема спроса; $i_{p}^{q}$ - индекс цены.

Подставляя в (6) значения из вектора-столбца $P_{\text {отеч}}$, который содержит индексы цен на отечественные товары и услуги, рассчитанные по (3), получим $n$ значений индекса изменения физических объемов спроса $\left(I_{q}\right)$, исходя из которых можно рассчитать новые значения вектора-столбца конечного использования ( $\left.Y_{\text {отеч}}\right)$.

Коэффициент эластичности $r$, конечно, различен для разных товаров и услуг, а также для внутреннего и внешнего рынков. Однако первоначально для самого простого случая мы исходим из того, что $r=\mathrm{const}$ для всех $n$ отраслей. О более реалистичном случае будет сказано ниже.

Следует отметить, что для дальнейших расчетов, по сути, должна рассматриваться система индексов цен, характеризующих как отечественные, так и импортные товары и услуги, а также учитывающих разницу между ценами на внутреннем и внешнем рынках:

- для отечественных товаров и услуг на внутреннем рынке следует брать индексы цен, рассчитанные по (3) и содержащиеся в $P_{\text {отеч}}$, которые характеризуют процессы удорожания ввиду роста цен на импортные материалы и комплектующие;

- для отечественных товаров и услуг, которые экспортируются, следует учесть, что в иностранной валюте их цена будет в случае девальвации национальной валюты ниже, однако эффект повышения цен ввиду более дорогих импортных элементов также должен быть учтен посредством деле- 
ния каждого элемента $P_{\text {отеч }}$ на коэффициент девальвации $\delta$;

- импортные товары на внутреннем рынке характеризуются индексами цен, содержащимися в векторе-столбце $P_{\text {имп }}$;

- на внешнем рынке цена импортных товаров будет оставаться неизменной (поэтому в табл. 1 в соответствующей ячейке указан единичный вектор-столбец).

Далее, исходя из (6), соответствующих коэффициентов эластичности и табл. 1, могут быть получены 4 набора $n$ индексов изменения физических объемов конечного спроса на отечественные и импортные товары и услуги.

Следует еще в общем виде пояснить, как полученные индексы цен и физического объема спроса могут быть использованы в дальнейших расчетах.

В общем виде произведение этих двух индексов дает индекс изменения спроса в стоимостном выражении:

$$
i_{p} \cdot i_{q}=\frac{p_{1}}{p_{0}} \cdot \frac{q_{1}}{q_{0}}=\frac{p_{1} q_{1}}{p_{0} q_{0}}
$$

где $p_{0}, p_{1}$ - цена в базовый и текущий период соответственно;

$q_{0}, q_{1}-$ физический объем спроса в базовый и текущий период соответственно.

Так как нас интересует в дальнейшем изменение какого-либо показателя в ценах базового периода, то будет осуществляться следующая операция: стоимостной показатель базового периода будет умножаться на индекс физического объема спроса (без умножения на индекс цен), что даст стоимостной показатель текущего периода в ценах базового периода:

$$
\begin{gathered}
p_{0} q_{0} \cdot i_{q}=p_{0} q_{0} \cdot \frac{q_{1}}{q_{0}}=p_{0} q_{1} \\
\text { Модель } 3 \\
\text { (базовая модель Леонтьева) }
\end{gathered}
$$

Ранее нами использована модель Леонтьева для оценки экономических последствий снижения спроса на внутреннем и внешнем рынках в части влияния на отраслевые показатели ВДС (Быков, Пархименко, Толкачев, 2020).

Классическое уравнение модели Леонтьева обычно представляют как

$$
A X+Y=X
$$

где $A$ - матрица технологических коэффициентов или прямых затрат, в которой элемент $a_{i j}$ показывает, сколько продукции $i$-й отрасли поставляется в $j$-ю отрасль для производства единицы продукции $j$-й отрасли;

$X$ - вектор-столбец выпуска товаров и услуг в основных ценах;

$Y$ - вектор-столбец конечного спроса (конечного использования) с размерностью, равной размерности вектора-столбца $X$. В конечный спрос включаются конечное потребление (домохозяйств, государственных учреждений и т. д.), накопление (основного капитала и оборотных средств) и экспорт.

Для белорусского межотраслевого баланса (9) можно переписать следующим образом:

$$
\left(A_{\text {отеч }}+A_{\text {имп }}\right) \cdot X+\left(Y_{\text {отеч }}+Y_{\text {имп }}\right)=X+I,
$$

где $Y_{\text {отеч }}-$ вектор-столбец, содержащий данные по конечному использованию (включая экспорт) отечественных товаров и услуг (размерностью 83 х 1);

Таблица 1

Индексы цен и индексы физического объема спроса, используемые в дальнейших расчетах

\begin{tabular}{|l|c|c|}
\hline \multicolumn{1}{|c|}{ Товары и услуги } & Внутренний рынок Беларуси & Экспорт из Беларуси \\
\hline \multirow{2}{*}{ Отечественные } & $\begin{array}{r}\text { Индексы цен }-P_{\text {отеч }} \\
\text { Индексы объема }-I_{\text {отеч }}^{D}\end{array}$ & Индексы цен $-\frac{1}{\delta} \cdot P_{\text {отеч }}$ \\
\hline \multirow{2}{*}{ Импортные } & Индексы цен $-P_{\text {имп }}$ & Индексы объема $-I_{\text {отеч }}^{E x p}$ \\
& Индексы объема $-I_{\text {имп }}^{D}$ & Индексы цен $-(1,1, \ldots, 1)^{T}$ \\
Индексы объема $-I_{\text {имп }}^{E x p}$
\end{tabular}

Примечание. Заглавные буквы $P$ и $I$ обозначают соответствующие векторы-столбцы размерности 83 х 1 , характеризующие набор индексов цен и индексов физического объема спроса.

Источник. Авторская разработка. 
$Y_{\text {имп }}$ - вектор-столбец, описывающий конечное использование (включая экспорт) импортных товаров и услуг (размерностью $83 \times 1)$;

$X$ - вектор-столбец, описывающий произведенный внутри страны общий объем выпуска товаров и услуг в основных ценах (размерностью 83 х 1);

I - вектор-столбец, описывающий общий объем импортируемых товаров и услуг (размерностью 83 х 1).

Очевидно, что импортные товары и услуги используются в рамках промежуточного потребления (при этом они линейно возрастают с ростом объемов выпуска внутри страны) и в рамках конечного использования (предполагается, что они не зависят от объема выпуска, а зависят от экзогенных факторов - предпочтений домашних хозяйств и т. д.), т. е. можно представить общий объем импорта как следующее матричное уравнение:

$$
I=A_{\text {имп }} \cdot X+Y_{\text {имп }}
$$

Если подставить (11) в (10) и решить (11) относительно $X$, получим:

$$
X=\left(E-A_{\text {отеч }}\right)^{-1} \cdot Y_{\text {отеч' }}
$$

где $E$ - единичная матрица соответствующей размерности 83 х 83 .

Матрица $\left(E-A_{\text {отеч }}\right)^{-1}$ в (6) является матрицей полных затрат отечественных товаров и услуг на единицу (1 рубль) конечного спроca. Учитывая изначальную заданность и относительную стабильность матрицы технологических коэффициентов (в данном случае - матрицы $\left.A_{\text {отеч}}\right)$, выпуск зависит исключительно от конечного спроса на отечественные товары и услуги (в том числе со стороны зарубежных потребителей).

Особый интерес представляет модификация (12), описывающая ситуацию, когда прирост конечного спроса на отечественные товары и услуги происходит исключительно за счет изменения внутреннего спроса, при неизменном экспорте. Для этого воспользуемся подстановкой

$$
Y_{\text {отеч }}=D_{\text {отеч }}+\operatorname{Exp}_{\text {отеч }}
$$

где $D_{\text {отеч }}$ - вектор-столбец внутреннего конечного спроса на отечественные товары и услуги (конечное потребление и накопление);

$\operatorname{Exp}_{\text {отеч }}$ - вектор-столбец экспорта отечественных товаров и услуг.

Исходя из (13), можно переписать (12) в общем случае в виде двух слагаемых: первое описывает изменения выпуска за счет изменения спроса на отечественные товары и услуги внутри страны, а второе - за счет изменения экспорта отечественных товаров и услуг:

$$
X=\left(E-A_{\text {огеч }}\right)^{-1} \cdot D_{\text {отеч }}+\left(E-A_{\text {огеч }}\right)^{-1} \cdot \operatorname{Exp}_{\text {огечं }} \text {. }
$$

По аналогии с (13) и (14) можно переписать (11) с учетом (12) следующим образом:

$$
I=A_{\text {имп }} \cdot X+D_{\text {имп }}+\operatorname{Exp}_{\text {имп }}
$$

Теперь можно определить выпуск $X$ и объем импорта $I$ для прогнозных значений конечного спроса в базовых ценах. Последние находятся на основе подхода, зафиксированного в (8), и рассчитанных в соответствии с (6) и табл. 1 значений индексов физического объема спроса:

$$
\begin{aligned}
& D_{\text {отеч }}^{1}=D_{\text {отеч }}^{0} \circ I_{\text {отеч }}^{D}, \\
& D_{\text {имп }}^{1}=D_{\text {имп }}^{0} \circ I_{\text {имп }}^{D}, \\
& \operatorname{Exp}_{\text {отеч }}^{1}=\operatorname{Exp}_{\text {отеч }}^{0} \circ I_{\text {огеч }}^{\operatorname{Exp},} \\
& \operatorname{Exp}_{\text {имп }}^{1}=\operatorname{Exp}_{\text {имп }}^{0} \circ I_{\text {имп }}^{\operatorname{Exp},}
\end{aligned}
$$

где о - символ произведения Адамара ${ }^{10}$.

Прогнозный объем экспорта (без учета чистых налогов на продукты) может быть найден суммированием прогнозных значений из (16):

$$
\operatorname{Exp}=\operatorname{Exp}_{\text {отеч }}^{1}+\operatorname{Exp}_{\text {имп }}^{1}
$$

При этом надо иметь в виду, что $E x p-$ вектор-столбец размерностью 83 х 1, т. е. он содержит объемы экспорта по каждой из $n$ отраслей. Сумма всех элементов этого векто-

10 «Бинарная операция над двумя матрицами одинаковой размерности, результатом которой является матрица той же размерности, в которой каждый элемент с индексами $i, j$ - это произведение элементов с индексами $i, j$ исходных матриц».URL: https://ru.wikipedia.org/wiki/Произведение_Адамара 
ра-столбца даст общий прогнозный объем экспорта по национальной экономике.

Торговое сальдо по каждой из $n$ отраслей может быть спрогнозировано на основе расчетов по (15) и (17) как

$$
T B=\operatorname{Exp}-I .
$$

Для получения торгового сальдо по национальной экономике в целом следует просуммировать все элементы вектора-столбца $T B$.

Конечный спрос на внутреннем рынке по каждой из $n$ отраслей

$$
D=D_{\text {отеч }}^{1}+D_{\text {имгі }}^{1}
$$

Для получения конечного спроса по национальной экономике в целом следует поступить аналогично случаям, приведенным выше, т. е. просуммировать все элементы вектора-столбца $D$.

Вероятно, особый интерес представляет прогнозирование расходов на конечное потребление домашних хозяйств в зарубежной валюте $\left(D_{U S D}\right)$, так как традиционно население пересчитывает свои доходы и расходы в доллары США, что может рассматриваться как важный психологический фактор благосостояния. Для каждой из $n$ отраслей данная величина может быть посчитана как

$$
H_{U S D}=\frac{1}{\delta} \cdot(S \circ D)
$$

где $S$ - вектор-столбец, содержащий доли расходов на конечное потребление домашних хозяйств в общем объеме внутреннего конечного спроса по каждой из $n$ отраслей.

Как и выше, необходимо просуммировать все элементы вектора-столбца $H_{U S D}$ для получения итоговой суммы по национальной экономике.

Индекс потребительских цен на внутреннем рынке может быть посчитан по варианту формулы Ласпейреса:

$$
\text { ИПЦ }=\frac{\sum_{i=1}^{n}\left(p_{i}^{\text {огеч }} \cdot h_{i}^{\text {огеч }}+p_{i}^{\text {имп }} \cdot h_{i}^{\text {имп }}\right)}{\sum_{i=1}^{n}\left(h_{i}^{\text {огеч }}+h_{i}^{\text {имп }}\right)} \cdot 100 \%
$$

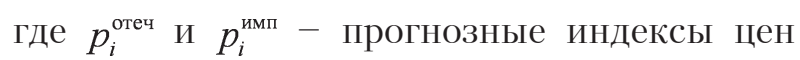
по $i$-отрасли для отечественных и импорт- ных товаров соответственно ( $i$-е элементы векторов-столбцов $P_{\text {отеч }}$ и $\left.P_{\text {имп }}\right)$;

$h_{i}^{\text {оге }}$ и $h_{i}^{\text {имп }}$ - размер расходов на конечное потребление домохозяйств в базовом периоде на отечественные и импортные товары соответственно.

Знание прогнозного значения объемов выпуска позволяет отыскать и другие макроэкономические показатели. Пожалуй, один из важнейших - общий размер валовой добавленной стоимости по отраслям, который может быть описан следующей системой уравнений:

$$
v a_{j}=x_{j}\left(1-\sum_{i=1}^{n} a_{i j}\right) \text { для } j=\overline{1, n},
$$

где $v a_{j}$ - валовая добавленная стоимость $j$-й отрасли;

$x_{j}-$ выпуск $j$-й отрасли, т. е. $j$-й элемент вектора-столбца $X$;

$a_{i j}$ - технологический коэффициент, т. е. $i j$-й элемент матрицы $A$.

В рамках модели Леонтьева валовая добавленная стоимость линейно зависит от выпуска отрасли при условии неизменности технологических коэффициентов: абсолютные значения валовой добавленной стоимости увеличиваются или снижаются в зависимости от объема выпуска, доля же этой стоимости в выпуске остается постоянной.

Примем за $v_{j}$ долю валовой добавленной стоимости в выпуске $j$-й отрасли и определим ее как

$$
v_{j}=\frac{v a_{j}}{x_{j}} .
$$

Пусть $V$ - вектор-столбец, содержащий в качестве элементов $v_{j}(j=\overline{1, n})$. Тогда систему уравнений (8) можно будет записать в матричной форме, используя произведение Адамара:

$$
V A=V \circ A
$$

Суммирование всех элементов векторастолбца $V A$ даст сумму валовой добавленной стоимости по национальной экономике в целом.

В случае необходимости набор рассчитываемых макроэкономических показателей может быть дополнен. 


\section{Подготовка белорусского МОБ к расчетам по модели Леонтьева}

Для того, чтобы можно было применить описанный выше подход, данные межотраслевого баланса по Республике Беларусь (самые свежие из доступных на текущий момент - за 2018 г.) следует привести к классическому (сбалансированному) представлению.

Как показывает анализ, в исходной матрице «Использование товаров и услуг в основных ценах» можно увидеть ряд дисбалансов, связанных с тем, что, в соответствии с методологическими положениями Белстата по построению таблиц «Затраты Выпуск», в строках 39-45 таблицы «Ресурсы товаров и услуг», относящихся к услугам торговли и транспорта, делается «погашающая запись общей величины наценки с отрицательным знаком», что отражается в дальнейшем и в таблице «Использование товаров и услуг в основных ценах», в которой все торговые и транспортные наценки отражаются в отдельных строках (строки 84-86).

В итоге наблюдается следующая картина дисбаланса - производится и импортируется услуг торговли и транспорта больше, чем используется в экономике (табл. 2).

Такой дисбаланс по строкам, относящимся к торговле и транспорту, нарушает основной принцип модели Леонтьева и не позволяет делать точные и надежные оценки.
Для устранения этого дисбаланса предлагается в таблице «Использование товаров и услуг в основных ценах» торговые и транспортные наценки перенести из строк 84-86 в соответствующие строки 39-45. При этом:

- торговые наценки делятся между строками 39-41 в пропорциях, задаваемых отношениями между этими наценками в столбце 88 таблицы «Ресурсы товаров и услуг»;

- транспортные наценки делятся между строками 42-45 в пропорциях, задаваемых отношениями между этими наценками в столбце 87 таблицы «Ресурсы товаров и услуг».

Следующий шаг - внесение торговых и транспортных наценок в таблицу «Использование импортных товаров и услуг». Балансировка делается следующим образом:

- рассчитывается по каждой строке из диапазона 42-45 разность между суммой использованных импортных товаров и услуг в таблице «Использование импортных товаров и услуг» и суммой импорта по этим строкам в таблице «Ресурсы товаров и услуг». Данная разность понимается как объем неучтенного в использовании импорта транспортных услуг (неучтенного как импорт, но учтенного как транспортная наценка в строке 85 таблицы «Использование товаров и услуг в основных ценах»);

- каждая такая сумма (неучтенного импорта транспортных услуг) разносится в каждую ячейку строки (включая проме-

Таблица 2

Данные из таблиц «Использование товаров и услуг в основных ценах и «Ресурсы товаров и услуг»

\begin{tabular}{|l|c|c|c|}
\hline \multicolumn{1}{|c|}{ Вид экономической деятельности } & № & $\begin{array}{c}\text { Всего использовано } \\
\text { ресурсов, товаров } \\
\text { и услуг в основных } \\
\text { ценах }\end{array}$ & $\begin{array}{c}\text { Ресурсы товаров } \\
\text { и услуг } \\
\text { в основных ценах }\end{array}$ \\
\hline $\begin{array}{l}\text { Ус луги по оптовой и розничной торговле } \\
\text { автомобилями и мотоциклами; услуги по ремонту } \\
\text { автомобилей и мотоциклов }\end{array}$ & 39 & 790802 & 2133289 \\
\hline $\begin{array}{l}\text { Услуги по оптовой торговле, кроме торговли } \\
\text { автомобилями и мотоциклами }\end{array}$ & 40 & 286421 & 10310711 \\
\hline $\begin{array}{l}\text { Услуги по розничной торговле, кроме торговли } \\
\text { автотранспортными средствами и мотоциклами }\end{array}$ & 41 & 0 & 9528772 \\
\hline $\begin{array}{l}\text { Услуги сухопутного транспорта и услуги } \\
\text { по транспортированию по трубопроводам }\end{array}$ & 42 & 9377967 & 10502695 \\
\hline Услуги водного транспорта & 43 & 2815 & 787735 \\
\hline Услуги воздушного транспорта & 44 & 880626 & 880626 \\
\hline $\begin{array}{l}\text { Услуги по складированию грузов } \\
\text { и вспомогательные транспортные услуги }\end{array}$ & 45 & 1626427 & 2739022 \\
\hline
\end{tabular}

Источник. Авторская разработка по данным межотраслевого баланса по Республике Беларусь за 2018 г. 
жуточное и конечное использование) пропорционально уже внесенным в эти ячейки значениям. Данная операция увеличивает сумму использованных товаров и услуг по строкам 42-45 до размеров импорта по соответствующим строкам в таблице «Ресурсы товаров и услуг».

После этого пересчитывается таблица «Использование отечественных товаров и услуг» как разность таблиц «Использование товаров и услуг в основных ценах» и «Использование импортных товаров и услуг».

Далее вычисляются матрицы прямых затрат, обратная матрица и выполняются все остальные действия по модели.

\section{Некоторые результаты расчетов}

Приводимые ниже расчеты по предложенной выше схеме следует рассматривать как сугубо укрупненные и приближенные, однако полученные результаты позволяют сделать ряд полезных для понимания макроэкономической динамики выводов.

По итогам осуществленных расчетов построены соответствующие функции реакции, отражающие изменение указанных макроэкономических показателей при разных уровнях обменного курса белорусского рубля (рис. 2).

Следует отдельно пояснить такой показатель, как «Прирост отношения торгового сальдо к ВДС (без учета налогов)». Модель

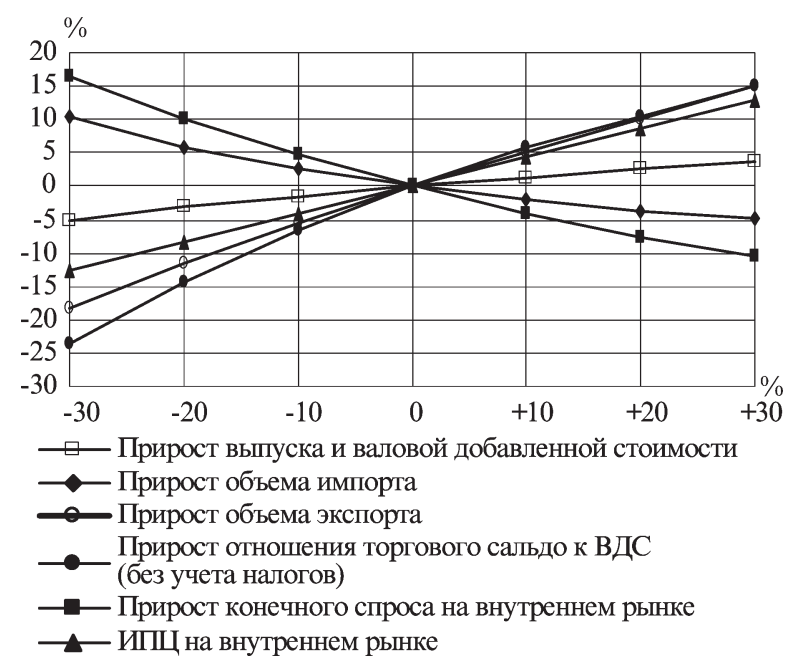

Рис. 2. Функции реакции, отражающие изменение макроэкономических показателей при разных уровнях обменного курса белорусского рубля

Источник. Авторская разработка. позволяет найти его абсолютные значения, однако для функций реакции авторы посчитали более наглядным перейти к относительной величине. В данном случае находилось отношение расчетного абсолютного значения торгового сальдо (положительного или отрицательного) к соответствующему значению валовой добавленной стоимости по экономике, причем для каждого варианта изменения обменного курса (от $-30 \%$ до $+30 \%$ ), после этого произведена корректировка таким образом, чтобы сальдо при неизменном курсе было равно нулю.

Расчеты показывают, что девальвация национальной валюты приводит к росту выпуска и ВДС за счет роста экспорта и положительному сальдо торгового баланса, однако при этом растет инфляция на внутреннем рынке (импортные и отечественные товары) и падает конечное использование на внутреннем рынке - конечное потребление и валовое накопление.

Исходя из рис. 2, можно увидеть, что удешевление белорусского рубля оказывает меньшее влияние, чем его удорожание относительно иностранной валюты. Данный эффект объясняется исключительно выбранным способом оценки изменения курса в процентах к фактическому значению. Например, при укреплении рубля на $50 \%$, допустим с 2,0 до 1,0 BYN/USD, при единичной эластичности спрос снизится в два раза; если же рубль девальвирует на $50 \%$, с 2,0 до 3,0 BYN/USD при той же эластичности, спрос вырастет лишь в 1,5 раза.

Особый интерес представляет реакция потребления домашних хозяйств на внутреннем рынке на изменения обменного курca, так как для населения именно этот показатель является наиболее чувствительным. При этом рассмотрим его значение в иностранной валюте (рис. 3).

Как видно из рисунка и как вполне ожидаемо, потребление, выраженное в иностранной валюте, растет при удорожании белорусского рубля и падает при его удешевлении относительно других валют мира.

Линейная аппроксимация данной функции показывает, что на каждый процентный пункт изменения обменного курса приходится примерно 0,16 п. п. изменения (в противоположном направлении) объема 


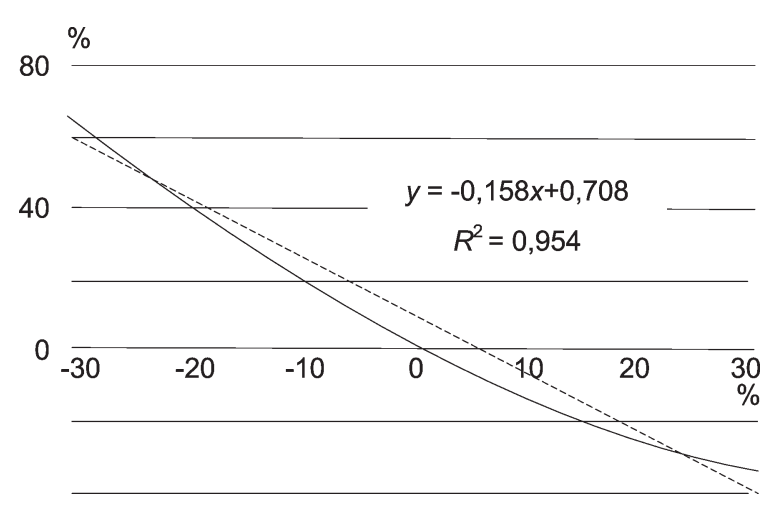

Рис. 3. Потребление домашних хозяйств на внутреннем рынке в иностранной валюте при разных уровнях обменного курса белорусского рубля

Источник. Авторская разработка.

потребления домашних хозяйств, измеряемого в иностранной валюте.

На рис. 4 представлено прогнозное изменение цен на отечественные товары и услуги при удешевлении национальной валюты по отношению к иностранным валютам в размере $10 \%$. Приведенные результаты в общем и целом укладываются в классическое представление о том, что в случае девальва- ции национальной валюты растут цены на импотируемые товары и услуги, а также на те отечественные товары и услуги, у которых высокая импортоемкость. Иными словами, девальвация приводит к росту цен на те, продукты, в производстве которых используется больше импортных компонентов. Если же производственная цепочка состоит в основном из товаров и услуг отечественного происхождения, девальвация в гораздо меньшей степени приводит к росту цен конечной продукции. Данный вывод представляется весьма важным для обоснования взаимосвязи денежно-кредитной и промышленной политики: «замыкание» отечественных цепочек добавленной стоимости путем импортозамещения и производства конечной продукции на основе отечественных ресурсов является условием достижения финансовой стабильности, поскольку делает экономику (в частности, показатели инфляции) менее зависимой от изменений валютного курса, которые часто связаны с внешними шоками.

На рис. 5 представлено прогнозное изменение (прирост) выпуска на отечественные товары и услуги (в базовых це-

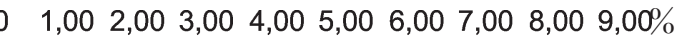

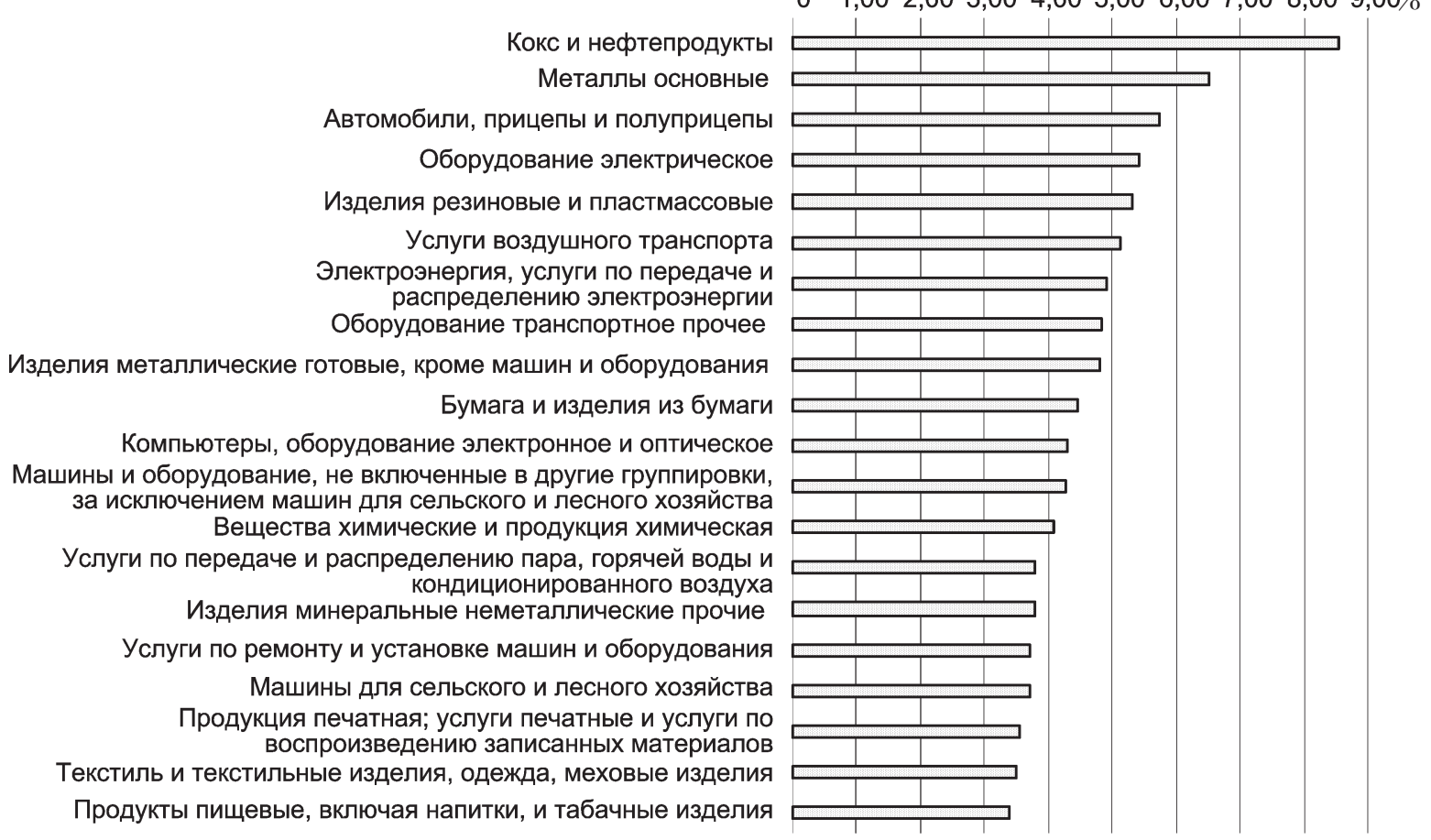

Рис. 4. Прогнозное изменение цен на отечественные товары и услуги при 10\% девальвации национальной валюты (наиболее значимые, по убыванию)

Источник. Авторская разработка. 


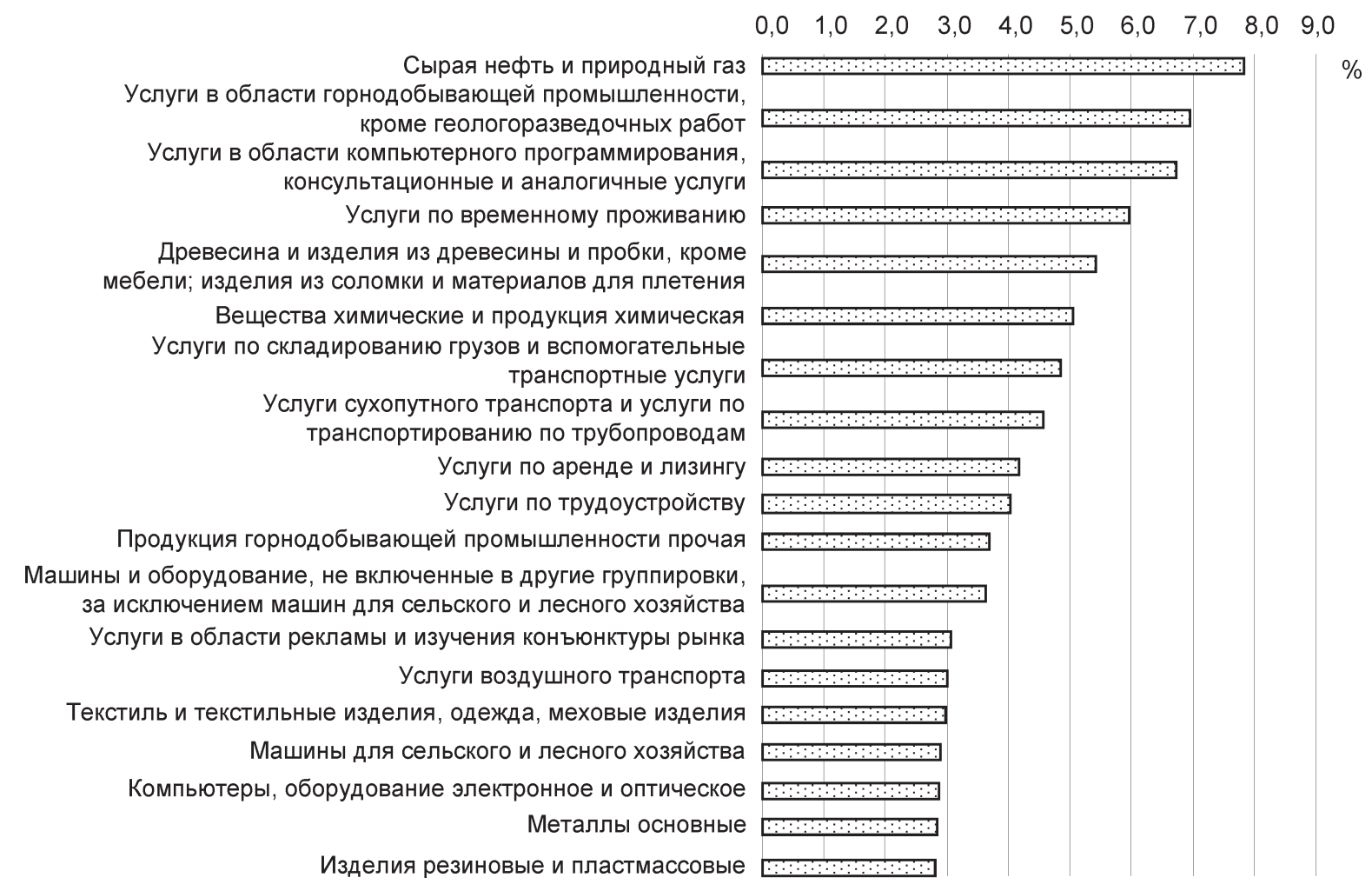

Рис. 5. Прогнозное изменение (прирост) выпуска отечественных товаров и услуг (в базовых ценах) при удешевлении национальной валюты в размере 10\%

Источник. Авторская разработка.

нах) при удешевлении национальной валюты по отношению к иностранным валютам в размере $10 \%$.

Полученный результат ожидаем в том смысле, что наибольший прирост выпуска приходится на более экспортоемкие виды экономической деятельности: именно они ввиду падения обменного курса отечественной валюты становятся более привлекательными для внешних покупателей, в следствие чего растут и объемы спроса.

Рис. 5 иллюстрирует отраслевой девальвационный эффект, при этом нужно понимать, что данный эффект имеет сугубо теоретическое представление. Разница с практикой определяется разницей между выбранными для расчета и реальными коэффициентами ценовой эластичности. Скорее всего, спрос на минеральные ресурсы характеризуется невысокой эластичностью $(r<1)$, поэтому реальный прирост выпуска окажется ниже расчетного. Спрос на услуги компьютерного программирования, возможно, высокоэластичный, однако увеличение спроса не обязательно будет сопровождаться ростом выпуска ввиду ограниченности производственных ресурсов - в данном случае свободных IT-разработчиков.

Учитывая сказанное, ожидаемый прирост ВДС вследствие девальвации может оказаться существенно меньше расчетного, показанного в правой части рис. 2.

\section{Ограничения методологии и направления будущих исследований}

Отметим, что в качестве базовых допущений рассмотренной методологии расчетов были приняты следующие.

1. Одинаковый коэффициент эластичности для всех групп продуктов (видов экономической деятельности). При этом он был выбран равным 1. Конечно, этот слишком упрощенный подход облегчает расчеты, но, по всей видимости, существенно искажает реальное положение дел. В дальнейшем требуется использование более точных эмпирических оценок коэффициентов эластичности по всем 83 видам экономи- 
ческой деятельности или хотя бы по их укрупненным группам.

2. Один единственный курс, т. е. одна валюта (пусть даже и композитная корзина валют), существенно искажает адекватное моделирование реальных международных торговых отношений Республики Беларусь. В дальнейших исследованиях требуется учет хотя бы трех основных валют (российский рубль, доллар США, евро) с попыткой связать основные импортируемые товары и услуги с конкретной валютой.

3. Возможность безграничного увеличения экспорта ввиду снижения цены отечественных товаров и услуг в случае удешевления белорусского рубля. На самом деле рынок по отдельным видам продукции может быть уже насыщенным и даже серьезное снижение цены не приведет к фактическому увеличению спроса.

4. Отсутствие временного лага между фактом изменения обменного курса и изменением спроса. Введение подобного лага было бы более реалистично. Однако по классической методологии «Затраты - Выпуск» моделирование лага не предусматривается и полученный результат следует рассматривать как оценку нового равновесного состояния. Таким образом, подобное предполагало бы некоторую модификацию самой методологии.

5. Допущение о полном удовлетворении изменившегося спроса за счет роста выпуска отечественных товаров и услуг. В действительности выпуск может быть ограничен производственными ресурсами либо отставать во времени от изменений спроса.

Указанные ограничения могут быть учтены при дальнейшем совершенствовании базовой модели. В любом случае данная модель представляется полезной в исследованиях взаимосвязи финансового и нефинансового секторов национальной экономики.

\section{СПИСОК ЛИТЕРАТУРЫ (REFERENCES)}

Быков А.А., Шаблинская Т.В. 2020. Декомпозиция факторов экономического роста, основанного на спросе, с применением методологии межотраслевого баланса. Белорусский экономический журнал. № 1. С. 4-21. [Bykau A.A., Shablinskaya T.V. 2020. Decomposition of demanddriven economic growth factors using input-output methodology. Belorusskiy ekonomicheskiy zhurnal. No 1. PP. 4-21. (In Russ.)]

Быков А.А., Пархименко В.А., Толкачев С.А. 2020. Влияние Covid-19 на российскую экономику: методологические подходы к оценке на основе межотраслевого баланса. Белорусский экономический журнал. № 2. С. 25-37. [Bykau A., Parkhimenka U., Tolkachev S. 2020. Influence of COVID-19 on the Russian economy: Methodological approaches to the assessment based on the input-output tables. Belorusskiy ekonomicheskiy zhurnal. No 2. PP. 25-37. (In Russ.)] DOI: 10.46782/1818-45102020-2-25-37

Alexander S.S. 1952. Effects of a deviation on the trade balance. International Monetary Fund Staff Papers. Vol. 2. PP. 263-278.

Ca'Zorzi M., Cap A., Mijakovic A., Rubaszek M. 2020. The predictive power of equilibrium exchange rate models. ECB Working Paper Series. No 2358. PP. 2-43.

Hauner D., Lee J., Takizawa H. 2014. In which exchange rate models do forecasters trust? Applied Economics Letters. Vol. 21. Iss. 18. PP. 13021308.

Leontief W. 1986. Input-output economics. New York; Oxford: Oxford University Press.

Miller R.E., Blair P.D. 2009. Input-output analysis: Foundations and extensions. Cambridge university press.

Reinhart C.M., Rogoff K.S. 2004. The modern history of exchange rate arrangements: A reinterpretation. The Quarterly Journal of Economics. Vol. 119. Iss. 1. PP. 1-48.

Ribeiro R., McCombie J., Lima G.T. 2017. A reconciliation proposal of demand-driven growth models in open economies. Journal of Economic Studies. Vol. 44. Iss. 2. PP. 226-244.

Thirlwall A. 2003. Trade, the Balance of Payments and Exchange Rate Policy in Developing Countries. Northampton, MA: Edward Elgar. P. 156.

Veyrune R., Kokenyne A., Habermeier K.F., Anderson H. 2009. Revised system for the classification of exchange rate arrangements. IMF Working Papers. PP. 1-18. 
In citation: Belorusskiy Economicheskiy zhurnal. 2020. No 3. PP. 58-73.

Belarusian Economic Journal. 2020. No 3. PP. 58-73.

\title{
IMPACT OF CHANGES IN THE NATIONAL CURRENCY EXCHANGE RATE ON MACROECONOMIC INDICATORS: ASSESSMENT BASED ON THE «INPUT - OUTPUT» METHODOLOGY
}

\author{
Uladzimir Parkhimenka ${ }^{1}$, Aliaksei Bykau ${ }^{2}$ \\ Authors affiliation: ${ }^{1}$ Belarusian State University of Informatics and Radioelectronics (Minsk, Belarus); \\ ${ }^{2}$ Belarusian State Economic University (Minsk, Belarus). \\ Corresponding author: Aliaksei Bykau (aliaksei.bykau@yandex.ru).
}

ABSTRACT. The purpose of this article is to quantify the impact of exchange rate fluctuations on the main macroeconomic indicators based on the input-output methodology. The assessment is carried out by solving the corresponding systems of equations in dual and direct Leontiev model based on the official data of the input-output tables of the Republic of Belarus for 2018. The main macroeconomic indicators in this context include: total output, gross value added, volume of imports and exports, trade balance, level of consumer prices, final demand in the domestic market. Based on the results of the calculations, the corresponding reaction functions were constructed, reflecting the change in the mentioned macroeconomic indicators for different levels of the exchange rate of the Belarusian ruble. The article also discusses the limitations of the proposed methodology and directions for future research.

KEYWORDS: input-output analysis, devaluation, inflation, macroeconomic indicators, national currency, exchange rate, exchange rate regime, trade balance, the economic growth.

JEL-code: C67, D57, E17, O41.

DOI: $10.46782 / 1818-4510-2020-3-58-73$

Received 10.06.2020 